\title{
Effects of the Feedline Position on Microstrip Patch Antenna Performance
}

\author{
Ali Recai Celik \\ Dicle University, Electrical and Electronics Engineering, Diyarbakir, Turkey
}

\begin{abstract}
In this study, it is aimed to demonstrate the effects of the feed line position on the operating frequency, return loss and bandwidth of the rectangular patch microstrip antenna. For this purpose, a compact-sized antenna that can operate at 2.4-2.45 $\mathrm{GHz}$ frequencies is designed in High Frequency Structure Simulator (HFSS) program. Then, the position of the feedline is changed horizontally and vertically, and its effects are observed. The results obtained after the modificaions are given and discussed. It is stated that the feed line position is a very important parameter that affects the basic characteristics of the antenna.
\end{abstract}

KEYWORDS: Microstrip Antenna, Return Loss, Bandwidth, Feedline, HFSS

\section{INTRODUCTION}

In recent years, due to the development of the wireless communication systems and the increase in information flow, the volume of the transmitted data has increased. Therefore, antennas with low return loss (RL), high bandwidth (BW) and small size are needed. Among the microwave antennas, microstrip antenna (MA) which has superior features compared to the others has been widely preferred for this aim.

MAs were first produced by Munson [1] and Howell [2], and their use began to increase in the 1980s [3]. Today, they are used especially in communication applications, Wi-Fi and Wi-Max technologies, satellite systems, radars and biomedical fields $[4,5]$.

Conventional MAs have a radiating patch on one side and a ground plane on the other. Between the two planes, there is a substrate containing the dielectric material. Due to their ease of design, they are often created using geometric patch shapes such as square, rectangle, circle and triangle [6-9]. MAs can be fed by a microstrip or coaxial line.

In this study, a MA having the rectangular patch and fed by the feedline method will be examined. It will be shown how the position of the feed point affects the characteristics of the antenna such as operating frequency, RL and BW.

\section{DESIGN PROCESS}

\section{A. Rectangular Patch $M A$}

The basic structure of a rectangular patch MA is shown in Figure 1. The width and length of the patch are expressed as ' $\mathrm{W}$ ' and ' $\mathrm{L}$ ', respectively. The thickness of the dielectric material is denoted by ' $h$ ' [9].

The operating frequencies of the antenna depend on its physical and electrical parameters. The relationships between the width, length, dielectric constant (relative permitivity, $\varepsilon_{r}$ ) and operating frequency $\left(f_{0}\right)$ of the MA are given in Equations (1-5) [10,11].

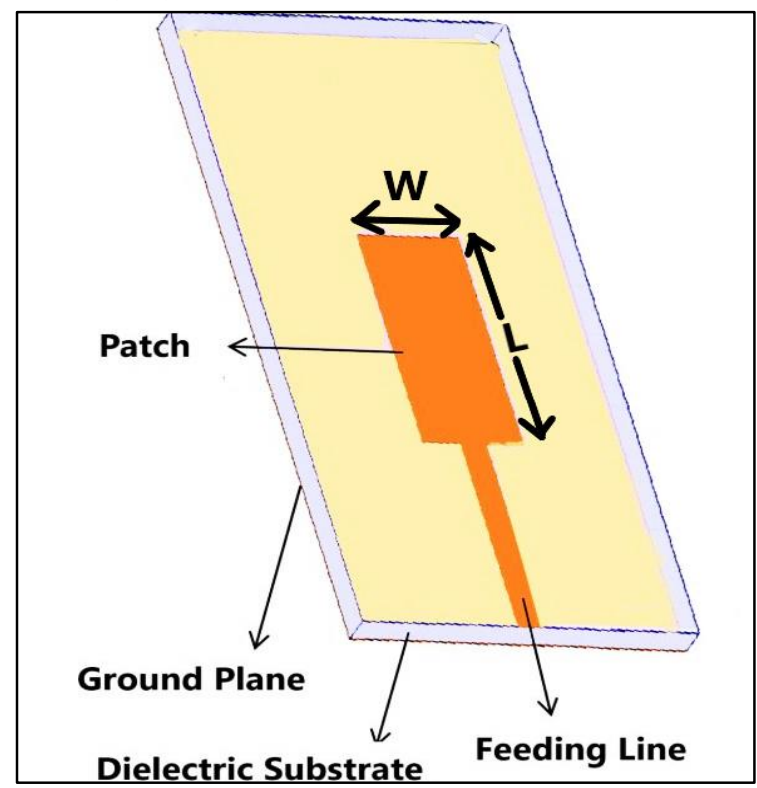

Figure 1. The structure of a rectangular patch MA

$$
\begin{aligned}
& W=\frac{c}{2 f_{0}\left[\frac{\left(\varepsilon_{r}+1\right)}{2}\right]^{1 / 2}} \\
& \varepsilon_{r_{e f f}}=\frac{\varepsilon_{r}+1}{2}+\frac{\varepsilon_{r}-1}{2}\left(1+\frac{12 h}{W}\right)^{-1 / 2} \\
& L_{e f f}=\left[\frac{c}{2 f_{0}\left(\varepsilon_{r_{e f f}}\right)^{1 / 2}}\right] \\
& \Delta L=0.412 h \frac{\left(\varepsilon_{r_{e f f}}+3\right)\left(\frac{W}{h}+0.264\right)}{\left(\varepsilon_{r_{e f f}}-0.258\right)\left(\frac{W}{h}+0.8\right)} \\
& L=L_{e f f}-2 \Delta L
\end{aligned}
$$


where $\boldsymbol{\varepsilon}_{\boldsymbol{r} e f f}, \boldsymbol{L}_{\text {eff }}$ and $\boldsymbol{h}$ are effective dielectric constant, effective length and height of the antenna, respectively.

\section{B. Design Parameters}

In order to calculate the dimensions of the antenna, firstly it must be determined at which frequencies we desire to work. In this study, a compact-sized antenna that can operate at 2.4$2.45 \mathrm{GHz}$ frequencies is considered as a reference. The height of this antenna is $1.6 \mathrm{~mm}$, and the dielectric constant of the substrate is 4.4 due to "FR4-Epoxy" material is selected as dielectric material [12]. If the mentioned values are used in the Eq. (1-5), W is calculated as $30 \mathrm{~mm}$ and $\mathrm{L}$ as $38 \mathrm{~mm}$, approximately. The overall size of the antenna is determined as $40 \times 50 \mathrm{~mm}^{2}$.

As mentioned previous section, the feedline method is used in the design. The input impedance and width of the transmission line are $50 \mathrm{Ohm}$ and $3 \mathrm{~mm}$, respectively. The designed antenna which has all these values is given in the Figure 2.

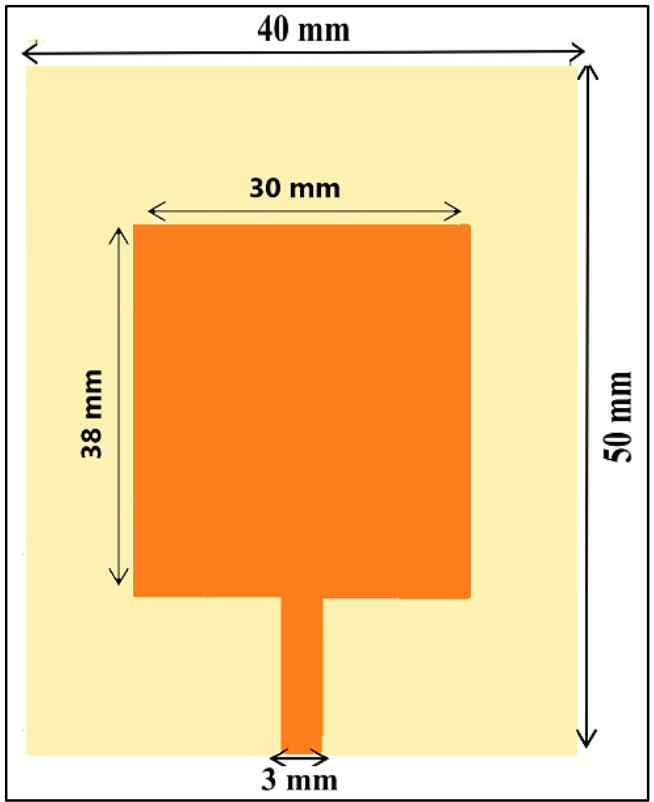

Figure 2. The front view of the reference antenna

The antenna shown in Figure 2 has been simulated in HighFrequency Structure Simulator (HFSS) program. HFSS is one of the widely used electromagnetic field simulation software. Electromagnetic problems can be solved quickly and successfully using this high-performance program. Both the near and far electromagnetic fields can be plotted, S parameters can be calculated, and antenna performance can be analysed with the HFSS [13].

The performance parameters such as RL, BW, gain and directivity can be changed with different feed point selections [14]. In accordance with the subject of this study, the position of the feedline will be changed horizontally and vertically, and its effects on the results will be observed. For this purpose, the line with its center at $20 \mathrm{~mm}$ and its left edge at $18.5 \mathrm{~mm}$ in Figure 2 is first moved horizontally. The new positions become $15.5 \mathrm{~mm}$ and $12.5 \mathrm{~mm}$, as seen in Figure 3.

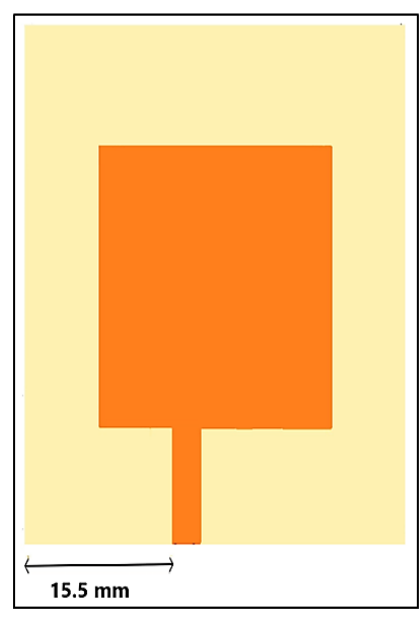

(a)

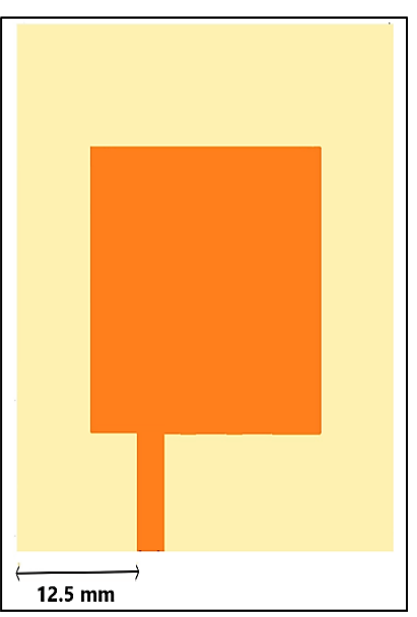

(b)
Figure 3. The new horizontally positions of the feedline

In another modification, the antenna is converted to inset fed shape. For this aim, the position of the feedline is changed vertically by notching method [15]. The sizes of the notches are $5 \times 1 \mathrm{~mm}^{2}$ and $5 \times 2 \mathrm{~mm}^{2}$ as seen in Figure 4 .
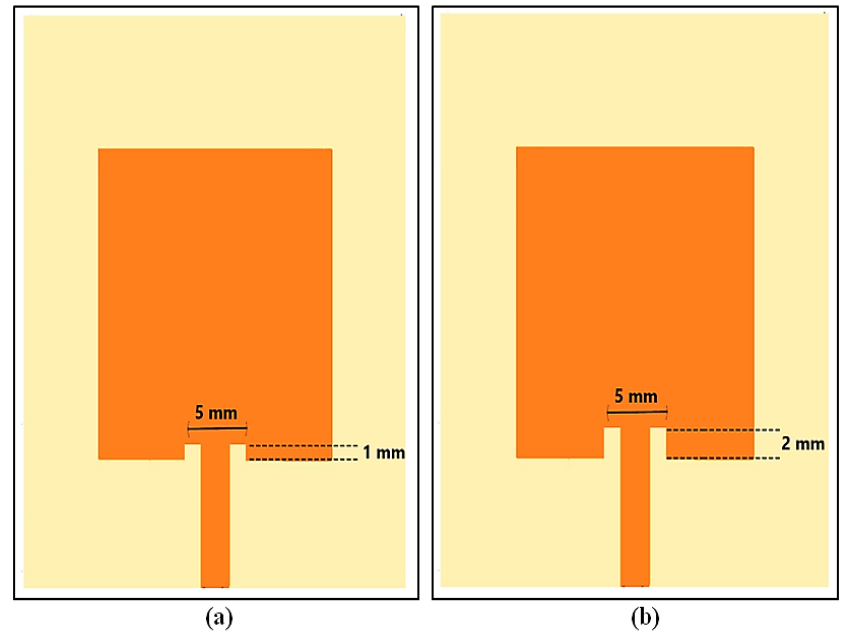

Figure 4. The new vertically positions of the feedline

\section{RESULTS AND DISCUSSIONS}

The RL plot of the antenna shown in Figure 2 is given in Figure 5. As expected, the antenna can operate at a frequency of $2.4 \mathrm{GHz}$. It has a return loss value of $-14 \mathrm{~dB}$ and a BW of $0.35 \mathrm{GHz}$.

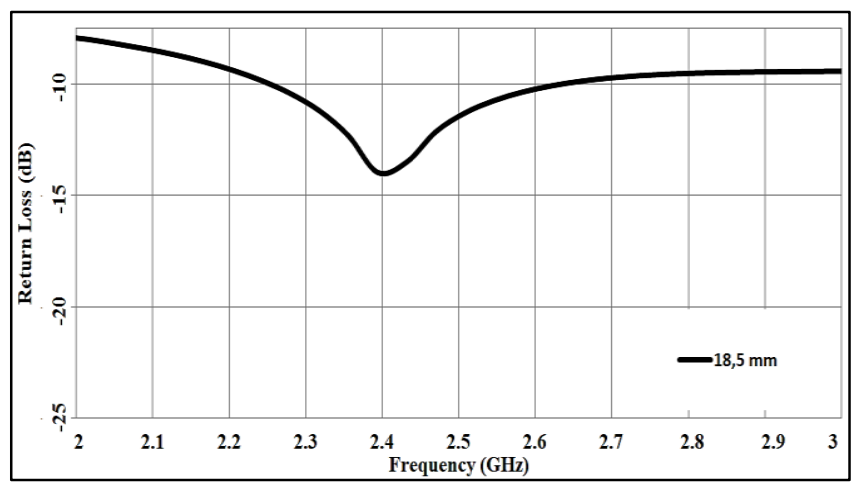

Figure 5. The return loss plot of the antenna before making any modification 
The new RL results obtained after shifting the left edge of the feed line to the $15.5 \mathrm{~mm}$ and $12.5 \mathrm{~mm}$ positions are given in Figure 6. As can be seen from this plot, changing the feedline position affects both the RL and BW. Accordingly, shifting it to $15.5 \mathrm{~mm}$, that is, its center point to $17 \mathrm{~mm}$, reduced the RL to $-21 \mathrm{~dB}$. The new $\mathrm{BW}$ is more than $0.9 \mathrm{~Hz}$. Although shifting the left edge of the feed line to $12.5 \mathrm{~mm}$ increased the BW, it can be said that the RL and sharpness are not at the desired levels.

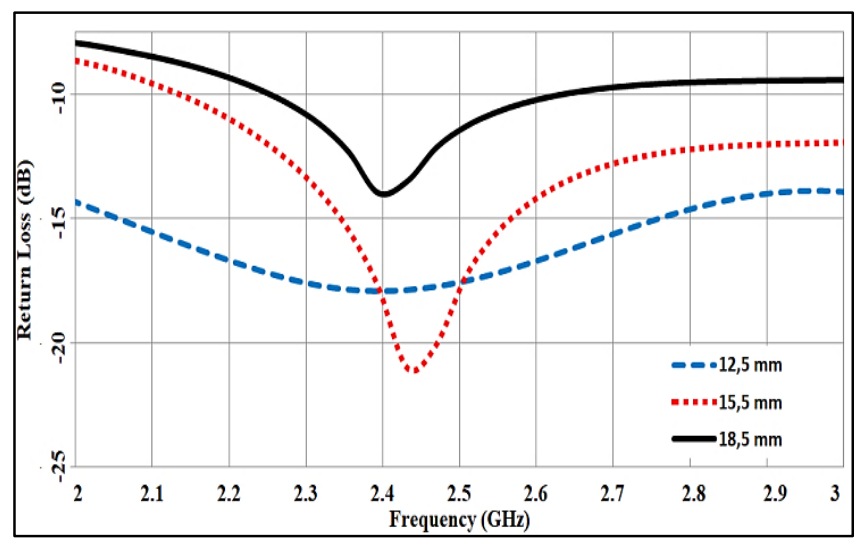

Figure 6. The new return loss plots of the antenna after shifting the feedline horizontally

The new RL results obtained after notching the transition point of the feed line and patch are given in Figure 7. As can be seen from this plot, thanks to the $5 \times 1 \mathrm{~mm}^{2}$ sized notch, the $\mathrm{RL}$ has been reduced to lower than $-25 \mathrm{~dB}$, and the $\mathrm{BW}$ has become more than $1 \mathrm{GHz}$. Furthermore, increasing the width of notch to $2 \mathrm{~mm}$ caused a new resonance to occur.

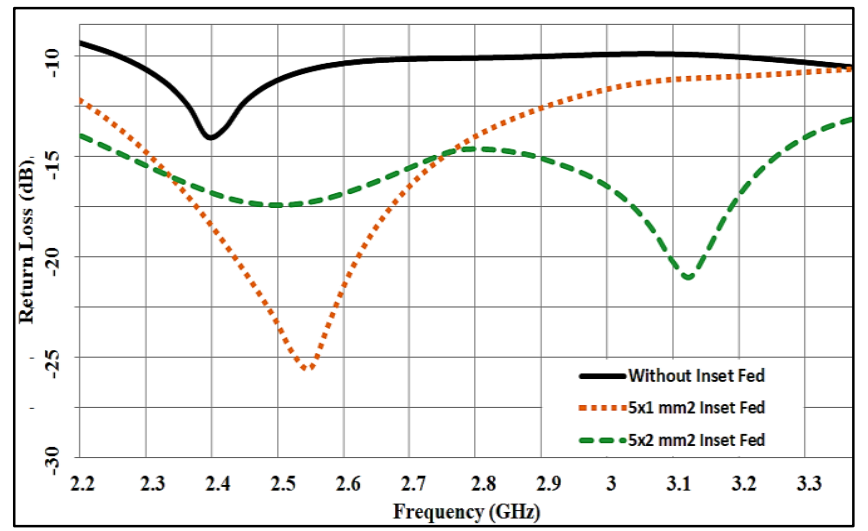

Figure 7. The new return loss plots of the antenna after using different sized notches

\section{CONCLUSIONS}

In this study, firstly, the necessity of using MAs in many areas was stated. Then, the rectangular patch MA was introduced, and its structure was given in details. A basic antenna operating at $2.4 \mathrm{GHz}$ was designed according to the some equations. Afterwards, various modifications were made to observe the effect of feedline position on the antenna performance. The results obtained after the changes were given and discussed. It has been demonstrated that the feed line position is a very important parameter that affects the operating frequency, RL and BW. In another study, it is planned to examine the effects of it on gain and directivity.

\section{REFERENCE}

1. Munson, R. E. (1973). "Single Slot Cavity Antennas Assembly," U.S. Patent No.3713162.

2. Howell, J. Q. (1975). "Microstrip Antennas," IEEE Transaction on Antennas and Propagation, Jan. 1975, pp.90-93.

3. James J. R., Hall, P. S. (1989). "Handbook of Microstrip Antennas", Peter Peregrinus Ltd, London.

4. Gupta R., Gupta, N. (2006). "Two Compact Microstrip Patch Antennas for 2.4 GHz Band - A Comparison", Microwave Review, vol. 12, no.2, pp. 29-31.

5. Zhang, H., Zhou, U., Wu, Z., Xin, H., Ziolkowski, R.W. (2010). "Designs of Ultra Wideband (UWB) Printed Elliptical Monopole", Microwave and Optical Technology Letters, vol.52, pp. 466-471.

6. Liu, L., Cheung, S.W., Yuk, T.I. (2011). "Bandwidth Improvements Using Ground Slots for Compact UWB Microstrip-fed Antennas", In Proceedings of the Progress in Electromagnetics Research Symposium (PIERS), Suzhou, China. pp. 1420-1423.

7. Baudha, S., Vishwakarma, D.K. (2016). "Bandwidth Enhancement of a Planar Monopole Microstrip Patch Antenna", International Journal of Microwave Wireless Technology, vol.8, pp. 237 242.

8. Mahendran, K., Gayathri, R., Sudarsan, H. (2021). "Design of Multi Band Triangular Microstrip Patch Antenna With Triangular Split Ring Resonator for S Band, C Band and X Band Applications", Microprocessors and Microsystems, Volume 80, Doi: 10.1016/j.micpro.2020.103400

9. Balanis, C.A. 1997. "Antenna Theory, Analysis and Design”, 2nd Edition.,Wiley, New York,

10. Ulaby, F. (2006). "Fundamentals of Applied Electromagnetics", 5th edition, Prentice Hall, Washington DC. USA.

11. Garg, R., Bhartia, P., Bahl, I., Ittipiboon, A. (2001). "Microstrip Antenna Design Handbook", Artech House Antennas and Propagation Library, Norwood. ISBN: 0-89006-513-6

12. FR4 Epoxy Properties, Available: https://www.microwaves101.com/encyclopedias/fr $-4$

13. Ansoft High Frequency Structure Simulator, (2014). "User Manual", Ansys Corporation, Canonsburg, PA, USA.

14. Karamanoglu, M., Abbak, M., Simsek, S. (2013). "A Planar Ultra-Wideband Monopole Antenna 
"Effects of the Feedline Position on Microstrip Patch Antenna Performance"

With Halfcircular Parasitic Patches" In Proceedings of the 13th Mediterranean Microwave Symposium (MMS); Saida, Lebanon.
15. Azim, R., Islam, M.T., Misran, N. (2013). "Microstrip Line-fed Printed Planar Monopole Antenna for UWB", Arabian Journal for Science and Engineering, vol.38, pp. 2415-2422. 